\title{
Evaluation of The Effects of Raisins and Hazelnuts Added To the Diet on Lipid Profiles and Anthropometric Measurements in Women with Hyperlipidemia
}

\author{
(i) Hande ÖNGÜN YILMAZ1 , io Bedia ÖZYILDIRIM²
}

1'istanbul Okan University Faculty of Medicine, Department of Nutrition and Dietetics, İstanbul, Turkey

${ }^{2}$ Bezmialem Vakıf Unicversity Faculty of Medicine, Department of Public Health, İstanbul , Turkey

\begin{abstract}
Objective: The positive effects of nuts and grape products on lipid profiles have been proved by epidemiological and clinical studies. However, studies investigating the effect of raisins on lipid profiles are limited. The aim of this study was to compare the effects of consuming a cardioprotective control diet, and the cardioprotective diet containing either raisins, hazelnuts, or a combination of raisins and hazelnuts in hyperlipidemic obese women in terms of lipid profiles and anthropometric measurements.

Methods: Thirty-seven hyperlipidemic obese women were involved in a parallel controlled randomized clinical trial. Participants were randomly divided into four groups. The control group consumed a cardioprotective diet for six weeks while the other participants consumed $50 \mathrm{~g} /$ day hazelnut, $50 \mathrm{~g} /$ day raisins or $50 \mathrm{~g} /$ day hazelnut $+50 \mathrm{~g} /$ day raisins in a cardioprotective diet. Blood lipids, blood glucose levels, blood pressure, and anthropometric measurements were measured at the beginning and at the end of the study.

Results: There was not any significant difference between groups in terms of lipid profiles, blood glucose, blood pressure and anthropometric measurements (all p $>0.05$ ). Compared with initial measurements, total cholesterol, low density lipoprotein cholesterol, and body mass index levels decreased statistically significantly (all $\mathrm{p}<0.05$ ) in all groups at the end of the study.

Conclusion: Because of the improvement on lipid profile and anthropometric measurements in four groups at the end of the study, it was concluded that consumption of hazelnut, raisins or combination of hazelnut andraisins can be recommended to hyperlipidemic individuals in addition to an appropriate diet program.
\end{abstract}

Keywords: Hazelnut, Raisins, cardioprotective diet, hyperlipidemia, lipid profile, anthropometric measurements

\section{Introduction}

Among chronic diseases, cardiovascular diseases (CVD) play an important role with high mortality and morbidity rates $(1,2)$. For CVD, the most important risk factors are high level of blood lipids and high blood pressure, unhealthy eating habits, physical inactivity and tobacco use (2). The total cholesterol level of 200$239 \mathrm{mg} / \mathrm{dL}$ and the low density lipoprotein (LDL) cholesterol level of $130-160 \mathrm{mg} / \mathrm{dL}$ are defined as borderline high values regarding hyperlipidemia and therapeutic lifestyle changes are recommended. These changes include; regulation of diet content, weight control, and increased physical activity (3). Only a single diet pattern is insufficient to regulate the diet content. Studies using the Mediterranean diet as a cardioprotective and healthy diet have shown that it reduces CVD risk. There is not a single
Address for Correspondence: Hande ÖNGÜN YILMAZ, İstanbul Okan University Faculty of Medicine, Department of Nutrition and Dietetics, İstanbul, Turkey

E-mail: hande.ongun@okan.edu.tr ORCID ID: orcid.org/0000-0002-3497-567X

Cite this article as: Öngün Yılmaz H, Özyıldırım B. Evaluation of The Effects of Raisins and Hazelnuts Added To the Diet on Lipid Profiles and Anthropometric Measurements in Women with Hyperlipidemia. Bezmialem Science 2019;7(4):294-306.

${ }^{\circ}$ Copyright 2019 by the Bezmiâlem Vakif University

Bezmiâlem Science published by Galenos Publishing House.
Received: 24.12 .2018

Accepted: 12.02 .2019 
type of Mediterranean diet. The common characteristics of Mediterranean diets are as follows: High consumption of vegetables, fruits, whole grain products, nuts, legumes, fish, olive oil; low consumption of red meat, moderate consumption of wine, dairy products, poultry, and eggs (4).

Nuts are high-energy foods which are rich in monounsaturated fatty acids (MUFA) and polyunsaturated fatty acids (PUFA). Besides the appropriate fatty acid composition, nuts contain a variety of bioactive substances: Plant protein, minerals, alphatocopherol, phenolic compounds and fiber (5). In many clinical and epidemiological studies, it has been shown that all nuts have cholesterol-lowering efficacy due to their appropriate fatty acid composition and bioactive components, and frequent consumption of them reduces the incidence of CVD $(6,7)$. Hazelnut has the highest unsaturated/saturated fatty acid ratio among nuts. Its oil pattern consists of 83.2\% MUFA, 9\% PUFA, while saturated fatty acid content is lower than $8 \%(8,9)$. MUFA are mainly oleic acid (82.7\%) and PUFA are omega-6 (8.9\%) and omega-3 $(0.1 \%)$ (8). In addition to its fatty acid content, hazelnut is a cardioprotective food (9-11) which involves nutrients such as soluble fiber, arginine, $\beta$-sitosterol, vitamin $\mathrm{E}$, folate, vitamin B6, potassium, and magnesium (10,11). Clinical studies with hazelnuts have proven positive effects on lipid profiles $(9,12-14)$.

Raisins, containing fructose and glucose equally are also rich in vitamins, minerals, fiber, and antioxidants (15). The results of several studies have provided that the consumption of grape and grape products has protective effects against chronic diseases. This effect is attributed to the antioxidant compounds in the grape $(16,17)$. Studies on the effect of grape-based products on lipid profiles in humans or animals have used products made from grapes (grape seed extract, grape juice, and wine) (1824). Studies using raisins have generally been carried out on the glycemic index and blood glucose $(15,25)$. Raisin has a high antioxidant capacity but the studies investigating its effect on lipid profile in humans are limited. According to our research hypothesis, a cardioprotective diet containing raisins is expected to lower blood lipids more than just a cardioprotective diet and raisins with hazelnuts more than just a hazelnut containing diet. The aim of this study was to compare the effects of consuming a cardioprotective control diet, and the cardioprotective diet containing either raisins, hazelnuts, or a combination of raisins and hazelnuts in hyperlipidemic obese women in terms of lipid profile, and anthropometric measurements.

\section{Methods}

\section{Subjects}

The study was carried out according to the principles of the Helsinki Declaration. All the research related procedures were approved by the İstanbul No 6 Ethics Committee of Clinical investigations in Bakırköy Dr. Sadi Konuk Training and Research Hospital with the decision dated 29.04.2013 and numbered $2013 / 05 / 01$. A protocol was signed with the approval of the İstanbul Public Health Directorate for the research conducted in a Family Health Centre, located in the Pendik Community Health Centre area.

The research was carried out with volunteer participants who registered to a family health center, attended for routine health check-ups between 11.11.2013-01.03.2014 and met the inclusion criteria of the survey. Non-pregnant women aged 40 years or older who had no accompanying chronic disease and did not use medication due to hyperlipidemia with body mass index $(\mathrm{BMI})>30 \mathrm{~kg} / \mathrm{m}^{2}$ with total cholesterol $>200 \mathrm{mg} / \mathrm{dL}$, LDL cholesterol level $>130 \mathrm{mg} / \mathrm{dL}$, fasting blood glucose $<110$ $\mathrm{mg} / \mathrm{dL}$ and systolic/diastolic blood pressure $<140 / 90 \mathrm{mmHg}$ were included in the study. The exclusion criteria were having a chronic illness (diabetes, hypertension, cancer, chronic kidney failure), using drugs due to hyperlipidemia and having allergies to specific foods (nuts, raisins). The health information of the participants was approved by the family physicians. The research was conducted with only women to prevent sex differences affecting the results of the research. According to the results of a study of cardiovascular disease and risk factors in Turkey (26), mean cholesterol concentrations in women aged 40-59 years were found to be $204 \mathrm{mg} / \mathrm{dL}$ in the research area. Because this result was above the hyperlipidemia limit value of $200 \mathrm{mg} / \mathrm{dL}$, the age of the participants was determined to be over 40 years.

For the study, 138 women who attended the Family Health Center for routine check-ups between 11.11.2013 and 01.03 .2014 , and who were over 40 years old, had BMI >30 kg/ $\mathrm{m}^{2}$ and had no accompanying chronic disease, were informed about the study and then blood lipids were examined from capillary blood after 12 hours of fasting. Ninety-four women were not included because their lipid profiles were normal (total cholesterol $<200 \mathrm{mg} / \mathrm{dL}$, LDL cholesterol level $<130 \mathrm{mg} / \mathrm{dL}$ ). Only 44 of these individuals fit the inclusion criteria of the survey. The participants were informed about the research and the experimental period was started after signing the informed consent form.

\section{Sample Size}

The sample size was determined to be 9 per group. In power analysis, when the probability of Type 1 error is 0.05 , the power of test is $82 \%$, Type 2 error is $17 \%$, SD of means is $15.16, \mathrm{SD}$ is 25.00 , and effect size is 0.61 . It was found that at least 9 individuals should be in each group in order to compare four groups $(27,28)$. The study was started with 11 individuals per group.

\section{Study Design}

For this parallel controlled randomized clinical trial, participants who fit the inclusion criteria were divided randomly into four groups according to registration number respectively: 1 hazelnut group (HG), 2 raisin group (RG), 3 hazelnut+RG (HRG), and 4 control group (CG).

At the beginning of the study, some socio-demographic information (age, marital status, working status, education 
status) and health condition (chronic diseases diagnosed by a doctor, drug and supplement usage, food allergy) of the participants were investigated with a questionnaire prepared by the researcher. The accuracy of health information was confirmed by the participants' family physicians.

Blood lipids are known to stabilize within 3 weeks (29). Clinical studies researching the effect of nuts on blood lipids lasted 4-8 weeks (11). Therefore, the experimental period of the research lasted 6 weeks.

HG consumed a cardioprotective diet with $50 \mathrm{~g}$ of hazelnuts added to their diet (HD), RG consumed a cardioprotective diet with $50 \mathrm{~g}$ of raisins added to their diet (RD), HRG consumed a cardioprotective diet with $50 \mathrm{~g}$ of hazelnuts and 50 $\mathrm{g}$ of raisins added to their diet (HRD) and the CG consumed a cardioprotective controlled diet. The American Food and Drug Administration recommend consuming $42.8 \mathrm{~g} /$ day of nuts to reduce the risk of CVD due to their positive effects on blood lipids (30). In clinical trials, 40-100 g of nuts were used daily to investigate the effects on blood lipids (11). In our study, 50 $\mathrm{g}$ of hazelnuts and the same amount of raisins were given to the participants per day.

According to the cardioprotective diet recommended in the context of lifestyle changes in the prevention of CVD, daily energy should be adjusted to maintain ideal body weight. The energy distribution taken from macronutrients should be as follows: $50-60 \%$ carbohydrates, $15 \%$ proteins, and $25-35 \%$ fats (3,31-33). In addition to these recommendations, whole grains, vegetables, fruits, fish, legumes, nuts are important nutrients to be consumed in terms of cardiovascular disease control (32). The diets of the research groups were prepared in accordance with this information. Daily diet menus designed by the researcher and consumed by the participants during the research are given in Table 1. Energy and nutritional values of the diets were calculated using the BeBIS7.2 program (Entwickeltan der Universitat Hohenheim, Stuttgart Copyright 2010 Dr. J. Erhardt, Stuttgart, Germany). Energy and nutritional values of the diets and the percentage of Recommended Dietary Allowance coverage (34) are given in Table 2. When diets are designed, it is aimed to be as equal as possible regarding energy and nutrients for all four groups. As shown in Table 2, diets are very close to each other in terms of energy, carbohydrate, protein, total fat and fiber content. Because hazelnuts are rich in total fat and MUFA, the diets of other groups are designed to be equal in terms of fat. Due to the differences in eating habits of the groups (such as using sunflower oil while cooking), the diets had differences in their PUFA and MUFA contents.For this reason, PUFA was higher in diets of the CG and RG, and MUFA was higher in diets containing hazelnut.

At the beginning of the study, the researcher gave the nutrition guide and daily diet menu to the participants according to their group; and explained the diet. Participants consumed the diets which were recommended to them according to their group. Only hazelnuts and raisins were provided by the researcher. In order to prevent cross-contamination between the groups, the participants were told not to consume the products of the other groups (the CG was told not to consume hazelnuts and raisins to; the HG was told not to consume raisins; and the RG was told not to consume hazelnuts ) and they were followed up weekly. Any change in physical activity was not recommended for the participants so as not to influence the result of the diet.

During the research, subjects were followed up weekly and their weekly required hazelnuts and raisins were provided by the researcher in daily $50 \mathrm{~g}$ packages, free of charge. Individuals were asked to fill out weekly product consumption schedules. In weekly checks, the researcher investigated product consumptions and dietary compliance. If the participants did not comply with the diets, they reported that to the researcher. Instructions about product consumption and diets were repeated in weekly checks.

\section{Biochemical Measurements}

At the beginning and at the end of the 6-week experimental period, after 12 hours of fasting and 10 minutes of rest, capillary blood was taken by the family physician from the participants' fingertips to analyze total cholesterol, LDL, HDL and triglyceride with refractometric photometric measuring system using CardioChek ${ }^{\odot}$ P. AAnalyzer (PTS Diagnostics, Indianapolis, USA) portable whole blood test system. The use of capillary blood for the measurement of blood lipids is valid and reliable (35). CardioCheck PA system uses a single reagent strip to measure the lipid profile. It separates plasma from red blood cells, then some of the plasma is directed to analytespecific reaction pads and lipid concentrations are determined by reflectance photometry. HDL is initially separated from LDL and VLDL fractions following precipitation by phosphotungstic acid. Total cholesterol and HDL cholesterol are both converted enzymatically to cholest-4-en-3-one and hydrogen peroxide. The peroxide then reacts with disubstituted aniline to form quinoneimine dyes. Triglyceride also undergoes enzymatic conversion to dihydroxyacetone phosphate and hydrogen peroxide. Its concentration is determined using the same color reaction as cholesterol and HDL. LDL is calculated using the Friedewald formula for samples with triglyceride concentrations. Fasting blood glucose is analyzed with GlukoDr (AGM-2100, China) blood glucose test meter. The GlucoDR reference device is the YSI 2300 Analyzer. Measurements were done five minutes after the blood was taken.

\section{Blood Pressure Measurements}

Individuals systolic and diastolic blood pressure were measured by the family nurse at the beginning and at the end of the 6 weeks after 10-minute rest with Omron Q142 Hem-1040-e Full Automatic Blood Pressure Monitor from each arm. Blood pressure measured in duplicate, the higher value was recorded.

\section{Anthropometric Measurements}

At the beginning and at the end of the 6-week experimental period weight, height, waist and hip circumference and skinfold thickness measurements were taken by the researcher. Measurements were repeated 3 times, mean values were recorded. 
Table 1. Daily diet menus designed by the researcher and consumed by the participants during the research

Daily HD menu

\section{Breakfast}

Tea

2 slice low fat white cheese (60

g)

3 slices whole grain bread (75 g)

Tomatoes (100 g) Cucumber (100 g)

\section{Snack}

Apple (120 g)

Lunch

\section{4 tablespoons vegetable}

(200 g)

4 tablespoon bulgur or pasta (40

g) (oil not added)

Salad (oil not added)

Half cup of yogurt (100 g)

2 slices whole grain bread (50 g)

\section{Snack}

1 packet of hazelnut (50 g)

\section{Dinner}

Chicken or fish (60 g)

4 tablespoons vegetable (200 g)

Salad (oil not added)

Half cup of yogurt (100 g)

3 slices whole grain bread (75 g)

Snack

Apple (120 g)

Orange (200 g)

Half cup of milk (100 g)
HD: Hazelnut diet, RD: Raisin diet, HRD: Hazelnut + raisins diet, CD: Control diet
Daily RD menu

\section{Breakfast}

Tea

2 slice low fat white cheese $(60 \mathrm{~g})$

3 slices whole grain bread $(75 \mathrm{~g})$

Tomatoes (100 g) Cucumber (100

g)

Snack

Apple (120 g)

Lunch

1 cup of soup (200 g)

4 tablespoons vegetable

(200 g)

2 tablespoon bulgur or pasta (20 g)

Salad (with olive oil)

Half cup of yogurt (100 g)

2 slices whole grain bread $(50 \mathrm{~g})$

\section{Snack}

1 packet of raisin (50 g)

\section{Dinner}

Chicken or fish (60 g)

4 tablespoons vegetable (200 g)

4 tablespoon bulgur or pasta (40 g)

Salad (oil not added)

Half cup of yogurt (100 g)

2 slices whole grain bread $(50 \mathrm{~g})$

\section{Snack}

\section{Orange (200 g)}

Half cup of milk (100 g)
Daily HRD menu

\section{Breakfast}

Tea

2 slice low fat white cheese (60 g)

3 slices whole grain bread (75 g)

Tomatoes (100 g) Cucumber (100

g)

\section{Snack}

Apple (120 g)

Lunch

4 tablespoons vegetable

(200 g)

4 tablespoon bulgur or pasta (40 g)

(oil not added)

Salad (oil not added)

Half cup of yogurt (100 g)

2 slices whole grain bread (50 g)

\section{Snack}

1 packet of hazelnut $(50 \mathrm{~g})$ and 1 packet of raisin $(50 \mathrm{~g})$

\section{Dinner}

Chicken or fish (60 g)

4 tablespoons vegetable (200 g)

Salad (oil not added)

Half cup of yogurt (100 g)

3 slices whole grain bread (75 g)

Daily CD menu

\section{Breakfast}

Tea

1 slice low fat white cheese

(30 g)

2 slices whole grain bread

(50 g)

Tomatoes (100 g) Cucumber (100 g)

\section{Snack}

Apple (120 g)

Lunch

1 cup of soup (200 g)

4 tablespoons vegetable

(200 g)

2 tablespoon bulgur or pasta

(20 g)

Salad (with olive oil)

Half cup of yogurt (100 g)

2 slices whole grain bread (50 g)

\section{Snack}

1 slice low fat white cheese (30 g)

2 slices whole grain bread (50 g)

Mandarin (125 g)

\section{Dinner}

Chicken or fish (60 g)

4 tablespoons vegetable $(200 \mathrm{~g})$

2 tablespoon bulgur or pasta (20 g)

Salad (with olive oil)

Half cup of yogurt (100 g)

2 slices whole grain bread (50 g)

Snack

Snack

\section{Orange (200 g)}

Orange (200 g)

Half cup of milk (100 g)
Half cup of milk (100 g)
Tanita BC 601 body analysis scale for weight measurement, Holtain Skinfold Caliper for skinfold thickness, and standard tape measure for waist and hip circumference were used. Weight and height measurements were used for calculating BMI, waist and hip measurements were used for calculating waist/hip ratio. Body fat mass and fat-free tissue mass were calculated by measuring the skinfold thicknesses from 4 regions (triceps, biceps, subscapular and suprailiac). 
Table 2. The energy and nutrients of the diets designed by the researcher and consumed by the participants during the research

\begin{tabular}{|c|c|c|c|c|c|c|c|c|c|}
\hline & $\mathrm{HD}$ & HD RDA\% & $\mathrm{RD}$ & $\begin{array}{l}\text { RD } \\
\text { RDA\% }\end{array}$ & HRD & $\begin{array}{l}\text { HRD } \\
\text { RDA\% }\end{array}$ & $C D$ & $\begin{array}{l}\text { CD } \\
\text { RDA\% }\end{array}$ & RDA \\
\hline Energy (kcal) & 1996.5 & 103 & 2015.2 & 104 & 1998.7 & 103 & 2013.5 & 104 & 1934.1 \\
\hline Protein (\%) & 14 & - & 13 & - & 14 & - & 14 & - & - \\
\hline $\mathrm{CHO}(\mathrm{g})$ & 255.8 & 93 & 266.7 & 97 & 256.9 & 93 & 264.4 & 96 & 276.1 \\
\hline Total fat (g) & و & 120 & 77.5 & 118 & 78.1 & 119 & 77.7 & 118 & 65.6 \\
\hline Total fat (\%) & 34 & - & 34 & - & 34 & - & 34 & - & - \\
\hline Total SFA (g) & 22.4 & - & 24.1 & - & 22.4 & - & 24.0 & - & - \\
\hline Total SFA (\%) & 10.1 & - & 10.7 & & 10.1 & & 10.7 & - & \\
\hline Total PUFA (\%) & 4.9 & - & 8.1 & - & 4.8 & - & 8.2 & - & - \\
\hline Omega 3 (g) & 1.2 & 109 & 1.2 & 109 & 1.1 & 100 & 1.3 & 118 & 1.1 \\
\hline Omega 6 (g) & 9.8 & 89 & 16.9 & 153 & 9.5 & 86 & 17.0 & 154 & 11.0 \\
\hline Cholesterol (mg) & 117.6 & - & 117.6 & - & 117.6 & - & 117.6 & - & - \\
\hline Fiber (g) & 39.8 & 133 & 31.0 & 103 & 34.1 & 114 & 34.9 & 116 & 30.0 \\
\hline Vitamin A ( $\mu g)$ & 1034.1 & 129 & 929.1 & 116 & 907.5 & 113 & 1095.2 & 137 & 801.0 \\
\hline Vitamin E (mg) & 26.9 & 224 & 24.0 & 200 & 25.9 & 216 & 24.2 & 202 & 12.0 \\
\hline Vitamin K ( $\mu g)$ & 150.3 & 251 & 153.2 & 255 & 147.2 & 245 & 151.9 & 252 & 60.0 \\
\hline Biotin ( $\mu$ ) & 79.9 & 178 & 55.2 & 123 & 73.8 & 164 & 59.6 & 133 & 45.0 \\
\hline Folic acid $(\mu g)$ & 360.1 & 90 & 318.5 & 80 & 339.6 & 85 & 354.4 & 86 & 400.0 \\
\hline Vitamin B12 $(\mu \mathrm{g})$ & 5.3 & 176 & 5.3 & 176 & 5.3 & 176 & 5.3 & 176 & 3.0 \\
\hline Vitamin C (mg) & 154.0 & 154 & 122.0 & 122 & 123.5 & 123 & 154.9 & 155 & 100.1 \\
\hline Sodium (mg) & 2193.6 & 110 & 2316.5 & 116 & 2182.2 & 109 & 2456.4 & 123 & 2001.0 \\
\hline Potassium (mg) & 3999.9 & 114 & 3460.5 & 99 & 3740.4 & 107 & 3637.5 & 104 & 3500.0 \\
\hline Calcium (mg) & 1259.9 & 126 & 1106.6 & 111 & 1213.4 & 121 & 1176.4 & 118 & 1001.0 \\
\hline Magnesium (mg) & 438.3 & 146 & 331.6 & 111 & 405.0 & 135 & 364.8 & 122 & 300.0 \\
\hline Phosphor (mg) & 1504.2 & 215 & 1330.2 & 190 & 1466.2 & 209 & 1394.4 & 199 & 701.0 \\
\hline Iron (mg) & 13.8 & 92 & 11.6 & 77 & 13.0 & 87 & 11.9 & 79 & 15.0 \\
\hline Zinc (mg) & 12.9 & 184 & 11.7 & 167 & 12.3 & 176 & 12.4 & 177 & 7.0 \\
\hline Copper (mg) & 2.0 & 158 & 1.3 & 106 & 1.9 & 152 & 1.3 & 106 & 1.3 \\
\hline Manganese (mg) & 9.1 & 260 & 5.8 & 166 & 8.5 & 242 & 6.5 & 186 & 3.5 \\
\hline lodine $(\mu g)$ & 66.4 & 33 & 62.2 & 31 & 61.7 & 31 & 64.5 & 32 & 200.1 \\
\hline
\end{tabular}

HD: Hazelnut diet, RD: Raisin diet, HRD: Hazelnut + raisins diet, CD: Control diet, SFA: Saturated fatty acids, MUFA: Mono-unsaturated fatty acids, PUFA: Poly-unsaturated fatty acids, RDA: Recommended dietary allowance, \%: Ratio of energy from nutrients 
Table 3. The baseline characteristics of the four groups

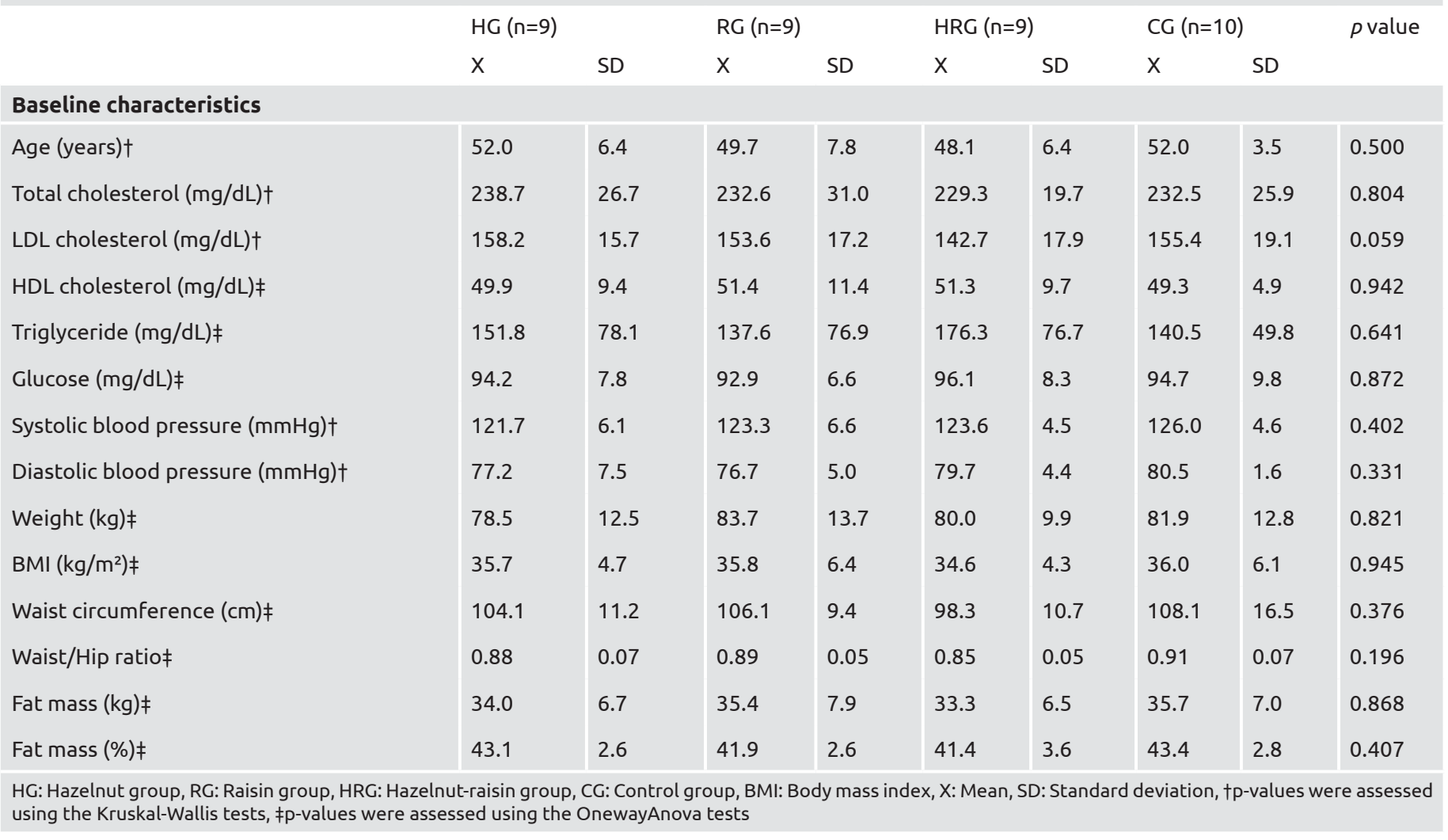

\section{Statistical Analysis}

The Statistical Package for the Social Sciences (SPSS version 16.0, Chicago, IL) program was used to statistically evaluate the data obtained from questionnaires, biochemical tests, and anthropometric measurements. Obtained continuous variables were expressed as mean $(\mathrm{X})$ and standard deviation (SD). Normality distribution of variables was analyzed with Kolmogorov-Smirnov. Oneway-ANOVA was used for the data with normal distribution and Kruskal-Wallis test was used for the data without normal distribution. The General Linear Model-Repeated Measures analysis was used for the evaluation of repeated measurements between the groups. For the evaluation of changes in measurement over time within groups (changes occurring in itself), General Linear Model-Repeated Measures analysis was used for data with normal distribution and the Wilcoxon test was used for data without normal distribution. To determine the significance of the study, statistical analyzes focused on comparing the changes that occurred in biochemical and anthropometric measurements between the four groups at the end of 6 weeks and comparing the self-generated changes in the groups compared with baseline measurements. The statistical significance level in the tests was evaluated as $\mathrm{p}<0.05$.

\section{Results}

Forty-four hyperlipidemic women participated in the study. The research was completed with a total of 37 individuals. Data from 9 individuals in the HG, 9 individuals in the RG, 9 individuals

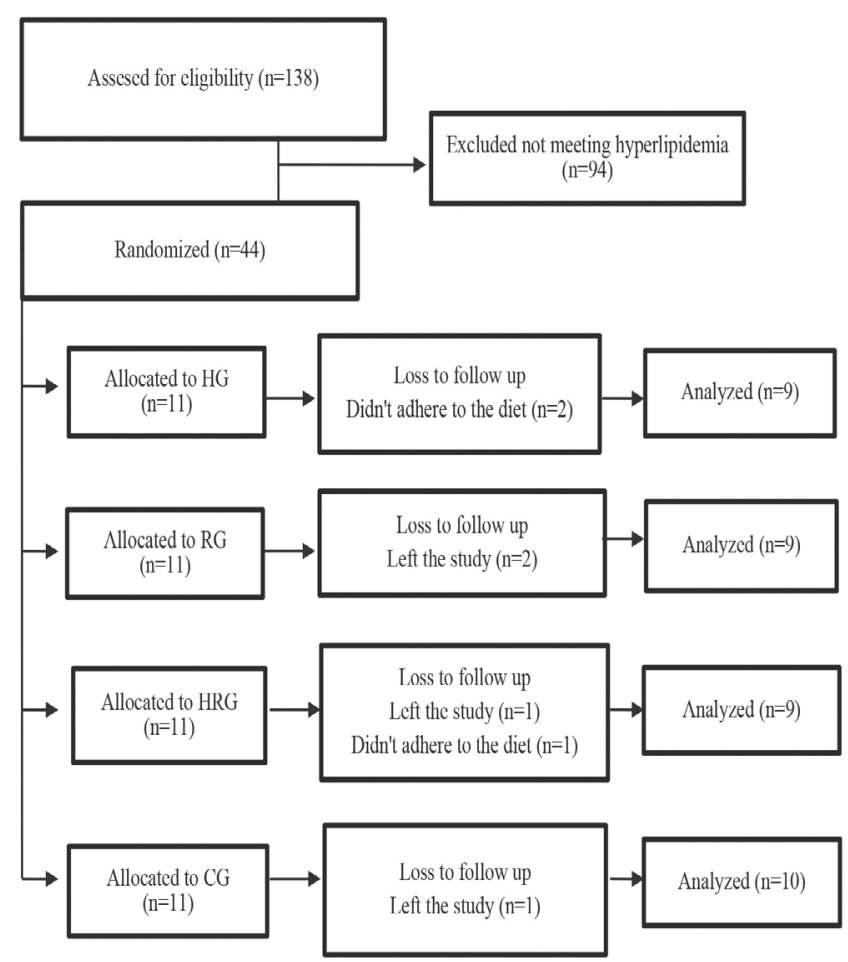

Figure 1. CONSORT 2010 flow diagram for the randomized controlled clinical tri

HG: Hazelnut group, RG: Raisin group, HRG: Hazelnut-raisin group, CG: Control group 
Table 4. Evaluation of changes in biochemical measurements, blood pressure and anthropometric measurements among groups

\begin{tabular}{|c|c|c|c|c|c|c|c|c|c|c|}
\hline & \multicolumn{2}{|l|}{$\begin{array}{l}\mathrm{HG} \\
(n=9)\end{array}$} & \multicolumn{2}{|l|}{$\begin{array}{l}\text { RG } \\
(n=9)\end{array}$} & \multicolumn{2}{|l|}{$\begin{array}{l}\text { HRG } \\
(n=9)\end{array}$} & \multicolumn{2}{|l|}{$\begin{array}{l}\text { CG } \\
(n=10)\end{array}$} & \multirow[t]{2}{*}{$\mathrm{F}$} & \multirow[t]{2}{*}{$p$ value* } \\
\hline & $x$ & SD & $x$ & SD & $x$ & SD & $x$ & SD & & \\
\hline \multicolumn{11}{|c|}{ Biochemical indicate } \\
\hline \multicolumn{11}{|c|}{ Total cholesterol (mg/dL) } \\
\hline $\begin{array}{l}\text { Baseline } \\
\text { After intervention }\end{array}$ & $\begin{array}{l}238.7 \\
216.9\end{array}$ & $\begin{array}{l}26.7 \\
29.7\end{array}$ & $\begin{array}{l}232.6 \\
210.0\end{array}$ & $\begin{array}{l}31.1 \\
18.5\end{array}$ & $\begin{array}{l}229.3 \\
204.7\end{array}$ & $\begin{array}{l}19.7 \\
34.4\end{array}$ & $\begin{array}{l}232.5 \\
216.8\end{array}$ & $\begin{array}{l}25.9 \\
35.1\end{array}$ & 0.391 & 0.760 \\
\hline $\begin{array}{l}\text { Baseline } \\
\text { After intervention }\end{array}$ & $\begin{array}{l}158.2 \\
139.7\end{array}$ & $\begin{array}{l}15.7 \\
27.2\end{array}$ & $\begin{array}{l}153.6 \\
134.8\end{array}$ & $\begin{array}{l}17.2 \\
16.2\end{array}$ & $\begin{array}{l}142.7 \\
123.0\end{array}$ & $\begin{array}{l}17.9 \\
22.3\end{array}$ & $\begin{array}{l}155.4 \\
136.4\end{array}$ & $\begin{array}{l}19.1 \\
31.2\end{array}$ & 0,007 & 0.999 \\
\hline \multicolumn{11}{|c|}{ HDL cholesterol (mg/dL) } \\
\hline $\begin{array}{l}\text { Baseline } \\
\text { After intervention }\end{array}$ & $\begin{array}{l}49.9 \\
52.6\end{array}$ & $\begin{array}{l}9.4 \\
11.3\end{array}$ & $\begin{array}{l}51.4 \\
49.7\end{array}$ & $\begin{array}{l}11.4 \\
8.9\end{array}$ & $\begin{array}{l}51.3 \\
52.4\end{array}$ & $\begin{array}{l}9.7 \\
11.3\end{array}$ & $\begin{array}{l}49.3 \\
47.4\end{array}$ & $\begin{array}{l}4.9 \\
6.6\end{array}$ & 0.784 & 0.511 \\
\hline \multicolumn{11}{|l|}{ Glucose (mg/dL) } \\
\hline $\begin{array}{l}\text { Baseline } \\
\text { After intervention }\end{array}$ & $\begin{array}{l}94.2 \\
93.3\end{array}$ & $\begin{array}{l}7.8 \\
11.7\end{array}$ & $\begin{array}{l}92.9 \\
101.6\end{array}$ & $\begin{array}{l}6.6 \\
6.9\end{array}$ & $\begin{array}{l}96.1 \\
93.1\end{array}$ & $\begin{array}{l}8.3 \\
10.4\end{array}$ & $\begin{array}{l}94.7 \\
98.5\end{array}$ & $\begin{array}{l}9.8 \\
8.2\end{array}$ & 2.427 & 0.083 \\
\hline \multicolumn{11}{|l|}{ Blood pressure } \\
\hline \multicolumn{11}{|l|}{ Systolic } \\
\hline $\begin{array}{l}\text { Baseline } \\
\text { After intervention }\end{array}$ & $\begin{array}{l}121.7 \\
121.1\end{array}$ & $\begin{array}{l}6.1 \\
5.5\end{array}$ & $\begin{array}{l}123.3 \\
119.4\end{array}$ & $\begin{array}{l}6.6 \\
7.3\end{array}$ & $\begin{array}{l}123.6 \\
115.6\end{array}$ & $\begin{array}{l}4.5 \\
8.5\end{array}$ & $\begin{array}{l}126.0 \\
122.0\end{array}$ & $\begin{array}{l}4.6 \\
7.9\end{array}$ & 1.236 & 0.312 \\
\hline \multicolumn{11}{|l|}{ Diastolic } \\
\hline \multicolumn{11}{|l|}{ BMI $\left(k g / m^{2}\right)$} \\
\hline $\begin{array}{l}\text { Baseline } \\
\text { After intervention }\end{array}$ & $\begin{array}{l}35.7 \\
34.5\end{array}$ & $\begin{array}{l}4.7 \\
4.7\end{array}$ & $\begin{array}{l}35.8 \\
35.1\end{array}$ & $\begin{array}{l}6.4 \\
6.2\end{array}$ & $\begin{array}{l}34.6 \\
33.6\end{array}$ & $\begin{array}{l}4.3 \\
4.0\end{array}$ & $\begin{array}{l}36.0 \\
34.9\end{array}$ & $\begin{array}{l}6.1 \\
5.7\end{array}$ & 0.560 & 0.645 \\
\hline \multicolumn{11}{|c|}{ Waist circumference (cm) } \\
\hline $\begin{array}{l}\text { Baseline } \\
\text { After intervention }\end{array}$ & $\begin{array}{l}104.1 \\
98.3\end{array}$ & $\begin{array}{l}11.2 \\
10.9\end{array}$ & $\begin{array}{l}106.1 \\
101.2\end{array}$ & $\begin{array}{l}9.4 \\
9.9\end{array}$ & $\begin{array}{l}98.3 \\
95.1\end{array}$ & $\begin{array}{l}10.7 \\
9.0\end{array}$ & $\begin{array}{l}108.1 \\
99.9\end{array}$ & $\begin{array}{l}16.5 \\
13.9\end{array}$ & 1.714 & 0.183 \\
\hline \multicolumn{11}{|l|}{ Waist/Hip ratio } \\
\hline $\begin{array}{l}\text { Baseline } \\
\text { After intervention }\end{array}$ & $\begin{array}{l}0.88 \\
0.85\end{array}$ & $\begin{array}{l}0.07 \\
0.04\end{array}$ & $\begin{array}{l}0.89 \\
0.86\end{array}$ & $\begin{array}{l}0.05 \\
0.04\end{array}$ & $\begin{array}{l}0.85 \\
0.85\end{array}$ & $\begin{array}{l}0.05 \\
0.05\end{array}$ & $\begin{array}{l}0.91 \\
0.87\end{array}$ & $\begin{array}{l}0.07 \\
0.04\end{array}$ & 1.852 & 0.157 \\
\hline \multicolumn{11}{|l|}{ Fat mass (kg) } \\
\hline $\begin{array}{l}\text { Baseline } \\
\text { After intervention }\end{array}$ & $\begin{array}{l}34.0 \\
31.8\end{array}$ & $\begin{array}{l}6.7 \\
6.2\end{array}$ & $\begin{array}{l}35.4 \\
34.1\end{array}$ & $\begin{array}{l}7.9 \\
7.9\end{array}$ & $\begin{array}{l}33.3 \\
31.1\end{array}$ & $\begin{array}{l}6.5 \\
6.0\end{array}$ & $\begin{array}{l}35.7 \\
33.5\end{array}$ & $\begin{array}{l}7.0 \\
6.6\end{array}$ & 1.232 & 0.314 \\
\hline \multicolumn{11}{|l|}{ Fat mass (\%) } \\
\hline $\begin{array}{l}\text { Baseline } \\
\text { After intervention }\end{array}$ & $\begin{array}{l}43.1 \\
41.7\end{array}$ & $\begin{array}{l}2.6 \\
2.5\end{array}$ & $\begin{array}{l}41.9 \\
41.1\end{array}$ & $\begin{array}{l}2.6 \\
3.3\end{array}$ & $\begin{array}{l}41.4 \\
39.6\end{array}$ & $\begin{array}{l}3.6 \\
3.7\end{array}$ & $\begin{array}{l}43.4 \\
41.9\end{array}$ & $\begin{array}{l}2.8 \\
2.9\end{array}$ & 1.036 & 0.389 \\
\hline
\end{tabular}

HG: Hazelnut group, RG: Raisin group, HRG: Hazelnut-raisin group, CG: Control group, BMI: Body mass index, X: Mean, SD: Standard deviation, *p values were assessed using the general linear model of variance for repeated measures 
in the HRG and 10 individuals in the CG were finally analyzed (see CONSORT flow-diagram in Figure 1).

Generally, the compliance rate was high. All of hazelnuts and raisins were consumed during the study in requested groups. No serious complications were reported during the study.

According to surveys conducted at the beginning of the research, it was determined that $94.6 \%(n=35)$ of the participants were educated for five years or less, $91.9 \%(\mathrm{n}=34)$ did not work and $89.2 \%(n=33)$ were married. None of the participants had chronic illness, used a drug, a supportive product such as vitamin-mineral usage, or had food allergy. The baseline characteristics (age, blood lipids, blood glucose, blood pressure, and anthropometric measurements) of the four groups are given in Table 3.

At the end of the study, changes in blood lipids, blood glucose, blood pressure and anthropometric measurements between groups were compared with general linear model repeated measures analysis. As shown in Table 4, there was no statistically significant difference between groups regarding the changes in blood lipids, blood glucose, blood pressure and anthropometric measurements at the end of the study (all $\mathrm{p}>0.05$ ).

The evaluation of initial and final blood lipids, blood glucose, blood pressure levels and anthropometric measurements by groups are given in Table 5. At the end of the study, total cholesterol and LDL cholesterol values were found to be statistically significantly (all $\mathrm{p}<0.05$ ) lower in all groups compared to the baseline measurements. The decrease in total cholesterol was $-21.8 \pm 13.9$ $\mathrm{mg} / \mathrm{dL}$ for the HG, $-22.6 \pm 27.7 \mathrm{mg} / \mathrm{dL}$ for the RG, $-24.7 \pm 20.4$ $\mathrm{mg} / \mathrm{dL}$ for the HRG, and $-15.7 \pm 10.9 \mathrm{mg} / \mathrm{dL}$ for the CG. There was an increase in HDL cholesterol values in HG and HRG $(2.7 \pm 3.8 \mathrm{mg} / \mathrm{dL}, 1.1 \pm 11.3 \mathrm{mg} / \mathrm{dL}$ respectively), and a decrease in $\mathrm{RG}$ and CG $(-1.86 .5 \mathrm{mg} / \mathrm{dL},-1.9 \pm 7.3 \mathrm{mg} / \mathrm{dL}$ respectively). Triglycerides decreased in HG, RG and HRG (-27.9 \pm 48.7 $\mathrm{mg} / \mathrm{dL}, 9.4 \pm 43.5 \mathrm{mg} / \mathrm{dL},-30.6 \pm 55.3 \mathrm{mg} / \mathrm{dl}$ respectively) and triglycerides increased in CG $(24.9 \pm 54.1 \mathrm{mg} / \mathrm{dL})$.

As shown in Table 4, at the end of the study there was no statistically significant difference between groups regarding the changes in weight, BMI, waist circumference, waist/hip ratio, and fat mass (all $\mathrm{p}>0.05$ ). As shown in Table 5, there was a statistically significant decrease in the BMI levels and fat masses $(\mathrm{kg})$ of all groups $(\mathrm{p}<0.05)$ at the end of the study. While there was a statistically significant decrease in terms of waist circumference in $C G, H G$ and $R G(p<0.05)$ compared to baseline measurements, there was not found a significant difference in HRG ( $p>0.05)$ (Table 5).

\section{Discussion}

The aim of the study was to evaluate the effects of raisin consumption in hyperlipidemic obese women regarding lipid profile and anthropometric measurements and compare it with hazelnut consumption and cardioprotective diet which are known to have beneficial effects on the lipid profile. As a result of the research, no significant difference was found between the four groups regarding blood lipids and anthropometric measurements (Table 4).
Nuts are rich in unsaturated fatty acids and most nuts include high MUFA. Because of having healthy fats, frequent nut intake lowers cholesterol, increases LDL resistance to oxidation, improves endothelial function and prevents CVD (36). Besides having appropriate fatty acid composition, nuts contain a variety of bioactive substances: plant protein, minerals, alphatocopherol, phenolic compounds and fiber (5). These bioactive components reduce oxidation, have anti-inflammatory effect, and improve endothelial function (6). More than 40 interventional studies on healthy or moderately hyperlipidemic subjects have shown that nuts raise HDL, lowers total cholesterol and LDL (37). An important result of the studies conducted on nuts is that the cholesterol-lowering effects of these products depend on the amount of consumption and they are especially effective in patients with high baseline LDL levels (7).

Among nuts, hazelnut is important for nutrition and health because of its MUFA content. Besides MUFA, other components including PUFA, phytosterols, and soluble dietary fiber, present in hazelnut, decrease plasma total cholesterol, and LDL. Hazelnut also contains fat-soluble bioactive components (tocopherols and phytosterols), minerals (magnesium, selenium), amino acids, antioxidants, and phytochemicals $(8,9)$. Moreover, vitamin E, found in hazelnut, has a cardioprotective effect (by inhibition of LDL oxidation) (9).

In a study, moderately hyperlipidemic subjects consumed daily $30 \mathrm{~g}$ hazelnut, 5 days a week for 4 weeks. Compared to baseline measurements, total cholesterol and LDL statistically significantly reduced, and HDL raised after hazelnut consumption (38). In this study, similar to study by Tey et al. (45), daily $50 \mathrm{~g}$ hazelnut consumption in HG statistically significantly decreased total cholesterol and LDL compared to initial measurements. Despite the increase in HDL and a decrease in triglyceride compared to baseline measurements, there was no statistically significant difference (Table 5).

The results of various studies have determined that the consumption of grape and grape products has a protective effect against CVD $(15,16,18-21)$. This effect is attributed to the antioxidant compounds found in the grape (17). Anthocyanin is an important component of raisin. A study comparing the effect of anthocyanin supplementation with the placebo in hyperlipidemic subjects revealed that the anthocyanin supplements reduced LDL cholesterol levels statistically significantly $(\mathrm{p}<0.001)$ compared to baseline measurements. LDL cholesterol reduced in a much more extent in the anthocyanin group $(\mathrm{p}=0.001)$. Supplementation of anthocyanin increased HDL cholesterol levels compared to baseline measurements. HDL raised in a much more extent in the anthocyanin group compared with the placebo group after the intervention $(\mathrm{p}=0.001)$ (39). Without changing the daily diet of healthy individuals, the effect of 6-week raisin consumption and walking on blood lipids was investigated in a study and at the end, the total cholesterol and LDL statistically significantly decreased compared to initial measurements and no difference was found between the groups (40). In this study, similar to the study by Puglisi et al. (40), a statistically significant reduction was detected in the total cholesterol and LDL levels 
Table 5. Effect of 6 weeks of diet intervention on biochemical indices, blood pressure and anthropometric measurements based on groups

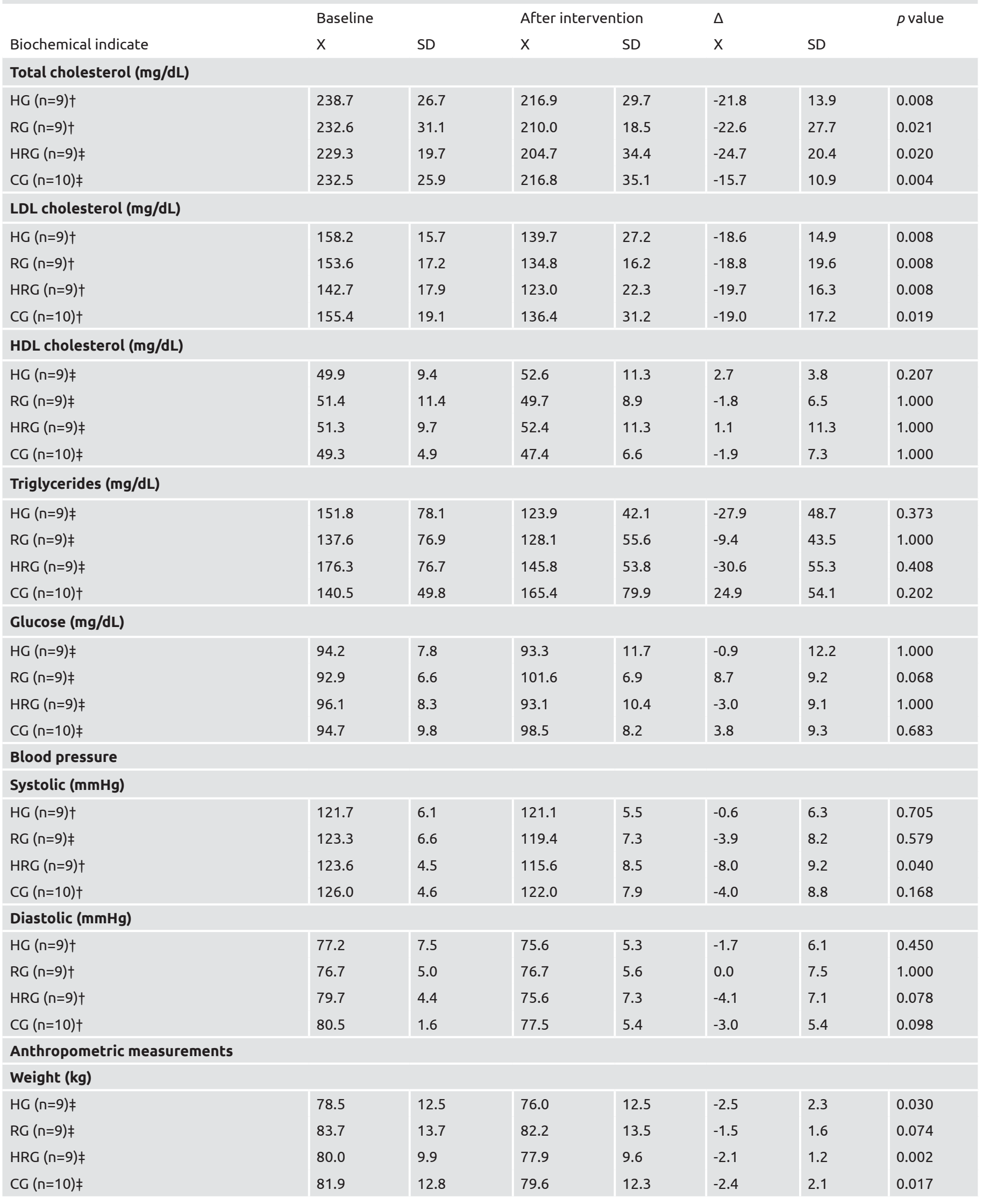


Table 5 contiuned

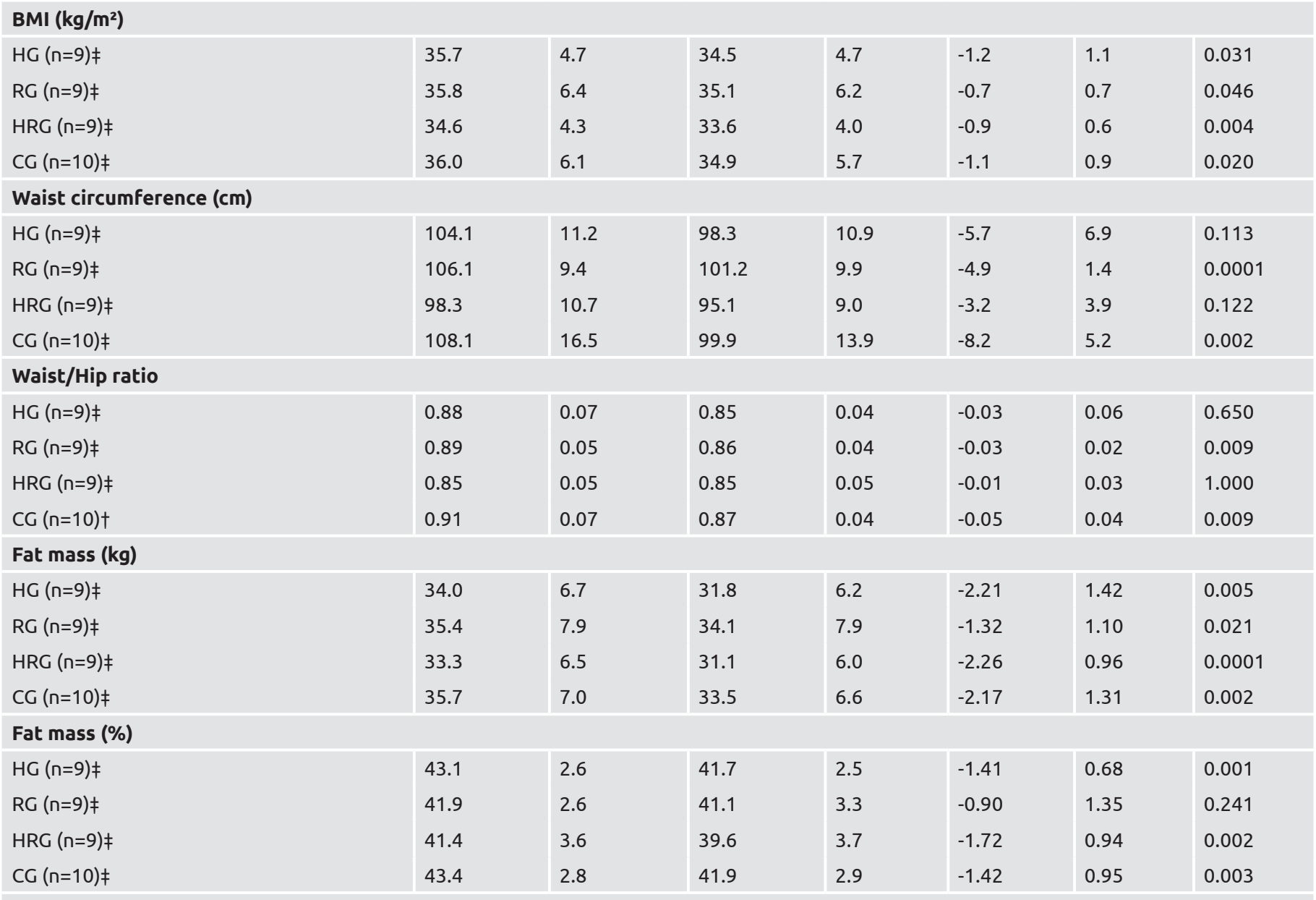

HG: Hazelnut group, RG: Raisin group, HRG: Hazelnut-raisin group, CG: Control group, BMI: Body mass index, X: Mean, SD: Standard deviation, $\Delta$ : Difference after intervention-baseline, $\mathrm{p}$ values show the general differences among baseline and diet periods for each group, $\dagger p$-values were assessed using the Wilcoxon tests, $\neq \mathrm{p}$-values were assessed using the general linear model of variance for repeated measures

of the RG compared to the baseline measurements and there was no statistically significant difference in terms of blood lipids between groups.

Studies using nut and grape products have shown that these products have beneficial effects on lipid profiles and reduce CVD risk $(6,7,10,19,38,41)$. As a result of these positive results, it was expected that the consumption of hazelnut and raisins together would decrease the risk of CVD. As a result of this research, positive changes in blood lipids were determined in HRG compared to initial measurements. As shown in Table 5, the total cholesterol and triglyceride levels of HRG decreased more than those of CG and the increase in HDL levels was found to be higher. However, when compared with the CG, the changes in the HRG were not statistically significant $(\mathrm{p}>0.05)$. Nevertheless, these results are thought to be important in decreasing CVD risk.

As a result of the research, positive changes were found compared to the initial measurements in lipid profiles and anthropometric measurements of the four groups, which consumed cardioprotective diets with similar energy content, containing either raisins, hazelnuts, or a combination of raisins and hazelnuts. The difference in blood lipids between dietary groups was not statistically significant. This may be due to the cardioprotective diet consumption in all groups.

Epidemiological studies have shown a negative relation between regular nut consumption and type 2 diabetes in women (42). Raisin is rich in fiber and fructose, and it belongs to the lowmiddle glycemic index nutrient class (15). It has been shown in some clinical trials that the consumption of raisins does not have any adverse effect on blood glucose $(15,43,44)$. As a result of this study, there was no statistically significant difference in fasting blood glucose compared to initial measurements. This result is also supporting previous studies.

Epidemiological and clinical studies have found a negative relation between the consumption of nuts $(5,45)$, dry fruits $(15,44)$, and blood pressure. There was no statistically significant change in systolic/diastolic blood pressures measured at baseline compared to the values measured after 6 weeks on the diet. Therefore, it was concluded that hazelnuts and raisins have no adverse effect on blood pressure.

At the end of our study, positive changes were found in the anthropometric measurements of all four groups. Long-term 
epidemiological and clinical studies have shown that there is no significant relationship between consumption of nuts and weight gain (46). In some studies conducted by adding nuts such as hazelnuts (12,38), pistachios (47), and peanuts (48) to daily diets, no significant difference was found in anthropometric measurements compared to baseline. At the end of our study, there was a statistically significant decrease in weight, BMI levels, waist circumference and fat mass in all groups as expected because all the individuals were obese and their diet contained recommended daily energy values. The decrease in waist circumference, an important risk factor for CVD, was also observed in all groups, but there was no significant difference in terms of waist circumference between the groups.

As shown in Table 4, there were no statistically significant differences in weight, BMI, and body fat mass changes between groups. It was concluded that the reason for not finding any difference between groups regarding the anthropometric measurements was the isocaloric diet consumption of all groups during the study.

\section{Study Limitations}

The sample size was considered among the limitations of research. Reasons such as stricted inclusion criteria for research, abandonment of research and individuals not complying with the diet limited the sample size negatively. There were some limitations for diets in this research: Participants consumed diet menus given to them by the researcher for 6 weeks. The dietary assessment was made only with the participants' declaration. The dietary record was not received. Individual compliance with diets and consumption of nuts and grapes given to them were checked with the product consumption schedule given to them at weekly controls, and no individual observations were made. Another limitation was that the amount of MUFA in diets of hazelnutconsuming groups was higher than the amount of PUFA in other groups. In order to demonstrate the effects of the products on blood lipids and anthropometric measurements clinically, it is suggested to increase the amount of the products, to have a larger study group and to have a longer study period

\section{Conclusion}

As a result of the research, there was no significant change in lipid profile and anthropometric measurements between the four groups. This may be due to consumption similar cardioprotective diet with similar energy content in all groups. Because of the improvement on lipid profile and anthropometric measurements of four groups at the end of the study, it was concluded that hazelnut and raisins consumption can be recommended in addition to an appropriate diet program to hyperlipidemic individuals.

\section{Ethics}

Ethics Committee Approval: All the research related procedures were approved by the İstanbul No 6 Ethics Committee of Clinical investigations in Bakırköy Dr. Sadi Konuk Training and Research Hospital with the decision dated 29.04.2013 and numbered 2013/05/01.

Informed Consent: The participants were informed about the research and the experimental period was started after signing the informed consent form.

Peer-review: Externally peer-reviewed.

\section{Authorship Contributions}

Concept: H.Ö.Y., B.Ö., Design: H.Ö.Y., B.Ö., Data Collection or Processing: H.Ö.Y., Analysis or Interpretation: H.Ö.Y., Literature Search: H.Ö.Y., Writing: H.Ö.Y., B.Ö.

Conflict of Interest: No conflict of interest was declared by the authors.

Financial Disclosure: The authors declared that this study received no financial support.

\section{References}

1. World Health Organization. Global status reporton noncommunicable diseases 2014. WHO Library Cataloguing-in-Publication Data, WHO. 2014 [cited 2016/8/12]; Available from: http://apps.who.int/ iris/bitstream/10665/148114/1/9789241564854_eng.pdf.

2. World Health Organization. Cardiovascular diseases (CVDs). WHO Media Centre, WHO.[cited 2016/11/8]; Available from: http:// www.who.int/mediacentre/factsheets/fs317/en/.

3. National Institutes of Health. National cholesterol education program. Detection, evaluation, and treatment of high blood cholesterol in adults (Adult treatment panel III) final report. NIH Publication. 2002 [cited 2013/2/10]; Available from: http://www. nhlbi.nih.gov/guidelines/cholesterol/atp3full.pdf.

4. Martinez-Gonzalez MA, Bes-Rastrolloa M. Dietary patterns, Mediterranean diet, and cardiovascular disease. Curr Opin Lipidol 2014;25:20-6.

5. Fischer S, Glei M. Potential health benefits of nuts. Ernaehrungs Umschau International 2013;60:206-15.

6. Ros E. Nuts and novel biomarkers of cardiovascular disease. Am J Clin Nutr 2009;89:1649-56.

7. Sabate J, Oda K, Ros E. Nut consumption and blood lipid levels. A pooled analysis of 25 intervention trial. Arch Intern Med 2010;170:821-7.

8. Alasalvar C, Shahidi F, Ohshima T, Wanasundara U, Yurttaş HC. Liyanapathirana CM, et al. Turkish tombul hazelnut (CorylusavellanaL.). 2. lipid characteristics and oxidative stability. J Agric Food Chem 2003;51:3797-805.

9. Mercanligil SM, Arslan P, Alasalvar C, Okut E, Akgül E, Pinar A, et al. Effects of hazelnut-enriched diet on plasma cholesterol and lipoprotein profiles in hypercholesterolemic adult men. Eur J Clin Nutr 2007;61:212-20.

10. Eagappan K, Sasikumar S. Therapeutic effects of nuts in various diseases. Int J Recent Sci Res 2014;5:190-7.

11. Griel AE, Kris-Etherton PM. Tree nuts and the lipid profile: a review of clinical studies. Br J Nutr 2006;96:68-78. 
12. Balaban Yücesan F, Örem A, Vanizor Kural B, Örem C, Turan I. Hazelnut consumption decreases the susceptibility of LDL to oxidation, plasma oxidized LDL level and increases the ratio of large/ small LDL in normolipidemic healthy subjects. Anadolu Kardiyol Derg 2010;10:28-35.

13. Tey SL, Brown R, Chisholm AW, Delahunty C, Gray AR, Williams SM. Effects of different forms of hazelnuts on blood lipids and $\alpha$-tocopherol concentrations in mildly hypercholesterolemic individuals. Eur J Clin Nutr 2011;65:117-24.

14. Örem A, Balaban Yücesan F, Örem C, Akcan B, VanizorKural B, Alasalvar C, et al. Hazelnut-enriched diet improves cardiovascular risk biomarkers beyond a lipid-lowering effect in hypercholesterolemic subjects. J Clin Lipidol 2013;7:123-31.

15. Anderson JW, Waters AR. Raisin consumption by humans: effects on glycemia and insulinemia and cardiovascular risk factors. J Food Sci 2013;78:11-7.

16. Perez-Jimenez J, Saura-Calixto F. Grape products and cardiovascular disease risk factors. Nutr Res Rev 2008;21:158-73.

17. Vislocky LM, Fernandez ML. Biomedical effects of grape products. Nutr Rev 2010;68:656-70.

18. Frederiksen H, Mortensen A, Schroder M, Frandsen H, Bysted A, Knuthsen P, et al. Effects of red grape skin and seed extract supplementation on atherosclerosis in Watanabe heritable hyperlipidemic rabbits. Mol Nutr Food Res 2007;51:564-71.

19. Zern TL, Wood RJ, Greene C, West KL, Liu Y, Aggarwal D, et al. Grape polyphenols exert a cardioprotective effect in preand postmenopausal women by lowering plasma lipids and reducingoxidative stress. J Nutr 2005;135:1911-7.

20. Perez-Jimenez J, Serrano J, Tabernero M, Arranz S, Diaz-Rubio ME, Garcia-Diz L, et al. Effects of grape antioxidant dietary fiber in cardiovascular disease risk factors. Nutrition 2008;24:646-53.

21. ZibaeeNezhad MJ, Mohammadi E, BabaieBeigi MA, Mirzamohammadi F, Salehi O. The effects of unripe grape juice on lipid profile improvement. Cholesterol 2012;2012:1-3.

22. Feringa HH, Laskey DA, Dickson JE, Coleman CI. The effect of grape seed extract on cardiovascular risk markers: a meta-analysis of randomized controlled trials. J Am Diet Assoc 2011;111:1173-81.

23. Tome-Carneiro J, Gonzálvez M, Larrosa M, Francisco J, GarcíaAlmagro FJ, Avilés-Plaza F, et al. Consumption of a grape extract supplement containing resveratrol decreases oxidized LDL and ApoB in patients undergoing primary prevention of cardiovascular disease: a triple-blind, 6-month follow-up, placebo-controlled, randomized trial. Mol Nutr Food Res 2012;56:810-21.

24. Queipo-Ortuno MI, Boto-Ordonez M, Murri M, GomezZumaquero JM, Clemente-Postigo M, Estruch R, et al. Influence of red wine polyphenols and ethanol on the gut microbiota ecology and biochemical biomarkers. Am J Clin Nutr 2012;95:1323-34.

25. Carughi A. Health benefits of sun-dried raisins. California: Health Research and Studies Center; 2008.

26. Onat A. Türk Halkında Lipid, Lipoprotein ve Apolipoproteinler. TEKHARF Çalışması, Türk Kardiyoloji Derneği. 2009: [cited 2013/4/11]; Available from: http://tekharf.org/2009.html.

27. Desu MM, Raghavarao D. Sample Size Methodology. New York: Academic Press; 1990.
28. Fleiss JL. The Design and Analysis of Clinical Experiments. New York: John Wiley \&Sons; 1986.

29. Sabate J, Haddad E, Tanzman JS, Jambazian P, Rajaram S. Serum lipid response to the graduated enrichment of a Step I diet with almonds: a randomized feding trial. Am J Clin Nutr 2003;77:137984.

30. Mukuddem-Petersen J, Oosthuizen W, JerlingJC. A Systematic Review of the Effects of Nuts on Blood Lipid Profiles in Humans. J Nutr 2005;135:2082-9.

31. American Heart Association Nutrition Committee, Lichtenstein AH, Apel LJ, Brands M, Carnethon M, Daniels S, et al. Diet and lifestyle recommendations revision 2006: A scientific statement from the American Heart Association Nutrition Committee. Circulation 2006;114:82-96

32. Mosca L, Benjamin EJ, Berra K, Bezanson JL, Dolor RJ, LloydJones DM, et al. Effectiveness-Based Guidelines for the Prevention of Cardiovascular Disease in Women- 2011 Update: A Guideline From the American Heart Association. Circulation 2011;123:1243-62.

33. Perk J, De Backer G, Gohlke H, Graham I, Reiner Z, Verschuren $M$, et al. European Guidelines on cardiovascular disease prevention in clinical practice (version 2012). The Fifth Joint Task Force of the European Society of Cardiology and Other Societies on Cardiovascular Disease Prevention in Clinical Practice (constituted by representatives of nine societies and by invited experts). Eur Heart J 2012;33:1635-701.

34. Otten JJ, Hellwig JP, Meyers LD (eds). Dietary Reference Intakes The Essential Guide to Nutrient Requirements. Washington: The National Academies Press; 2006.

35. Parikh P, Mochari H, Mosca L. Clinical utility of a fingerstick technology to identify individuals with abnormal blood lipids and high-sensitivity c-reactive protein levels. Am J Health Promot 2009;23:279-82.

36. Ros E, Mataix J. Fatty acid composition of nuts - implications for cardiovascular health. Br J Nutr 2006;96:29-35.

37. Bruckert E, Rosenbaum D. Lowering LDL-cholesterol through diet: potential role in the statin era. Curr Opin Lipidol 2011;22:43-8.

38. Tey SL, Brown R, Gray A, Chisholm AW, Delahunty C. Nuts Improve Diet Quality Compared to Other Energy-Dense Snacks While Maintaining Body Weight. J Nutr Metab 2011;2011:1-11.

39. Qin Y, Xia M, Ma J, Hao Y, Liu J, Mou H, et al. Anthocyanin supplementation improves serum LDL- and HDL-cholesterol concentrations associated with the inhibition of cholesteryl ester transfer protein in dyslipidemic subjects. Am J Clin Nutr 2009;90:485-92.

40. Puglisi MJ, Vaishnav U, Shrestha S, Torres-Gonzalez M, Wood RJ, Volek JS, et al. Raisins and additional walking have distinct effects on plasma lipids and inflammatory cytokines. Lipids in Health Dis 2008;7:1-9.

41. Rajesh V, Perumal P, Aruna P. Hypolipidemic and antioxidant activity of grape skin extract and resveratrol on rats fed with high-fat diet. Orient Pharm Exp Med 2013;13:11-20.

42. Jiang R, Manson JE, Stamfer MJ, Liu S, Willett WC, Hu FD. Nut and peanut butter consumption and risk of type 2 diabetes in women. JAMA 2002;288:2554-60. 
43. Kim Y, Hertzler SR, Byrne HK, Mattern CO. Raisins are a low to moderate glycemic index food with a correspondingly low insulin index. Nutr Res 2008;28:304-8.

44. Anderson JW, Weiter KM, Christian AL, Ritchey MB, Bays HE. Raisins compared with other snack effects on glycemia and blood pressure: a randomized, controlled trial. Postgrad Med 2014;126:3743.

45. Tey SL, Gray A, Chisholm AW, Delahunty C, Brown R. The Dose of hazelnuts influences acceptance and diet quality but not inflammatory markers and body composition in overweight and obese individuals. J Nutr 2013;143:1254-62.

46. Martinez-Gonzalez MA, Bes-Rastrollo M. Nut consumption, weight gain and obesity: Epidemiological evidence. Nutr Metab Cardiovasc Dis $2011 ; 21: 40-5$.

47. Sheridan MJ, Cooper JN, Erario M, Cheifetz CE. Pistachio nut consumption and serum lipid levels. J Am Coll Nutr 2007;26:14-48.

48. McKiernan F, Lokko P, Kuevi A, Sales, RL, Costa NMB, Bressan J, et al. Effects of peanut processing on body weight and fasting plasma lipids. Br J Nutr 2010;104:418-26. 